\title{
A Millennial Summer Temperature Reconstruction for the Eastern Tibetan Plateau from Tree-Ring Width*
}

\author{
JIANGLIN WANG AND BAO YANG \\ Key Laboratory of Desert and Desertification, Cold and Arid Regions Environmental and Engineering \\ Research Institute, Chinese Academy of Sciences, Lanzhou, Gansu, China \\ FREDRIK CHARPENTIER LJUNGQVIST \\ Department of History, and Bolin Centre for Climate Research, Stockholm University, Stockholm, Sweden
}

(Manuscript received 30 October 2014, in final form 21 March 2015)

\begin{abstract}
Although tree-ring-width-based temperature reconstructions of centennial-to-millennial length have previously been published for many parts of the eastern Tibetan Plateau (ETP), a millennium-long regional-scale composite reconstruction with annual resolution has so far been lacking. Here, the authors present a reconstruction of June-August (JJA) temperature variability over the ETP for the period AD 1000-2005 using a nested composite-plus-scale (CPS) approach to 12 temperature-sensitive tree-ring width chronologies, including 946 individual tree-ring width series. The composite reconstruction reveals warm episodes occurring during much of the sixteenth, nineteenth, and twentieth centuries and cold episodes during much of the eleventh, seventeenth, and eighteenth centuries. The period AD 1996-2005 is likely the warmest decade in the context of the past millennium. The authors explore the influence of possible forcings, finding only a weak direct relationship of temperature changes over the ETP with solar forcing at multidecadal time scales but a robust inphase relationship with the Atlantic multidecadal oscillation (AMO) during the past millennium. This suggests that the AMO may play an important role in controlling summer temperature variability over the ETP at multidecadal time scales. A comparison with temperature reconstructions from the higher latitudes of East Asia, central-eastern China, and the whole of the Northern Hemisphere shows that the cold eleventh century and the warm nineteenth century prevailing over ETP are somewhat unique, suggesting regional specific characteristics of the temperature variability in this region. This result highlights the need to further increase the number of millennium-long, high-resolution temperature records from East Asia.
\end{abstract}

\section{Introduction}

Millennia-long temperature reconstructions on regionalto-global scales provide important information for evaluating the performance of climate model simulations and can potentially offer an opportunity to reduce uncertainties in future climate change projections (Braconnot et al. 2012; Coats et al. 2013; Fernández-Donado et al. 2013; Phipps

\footnotetext{
* Supplemental information related to this paper is available at the Journals Online website: http://dx.doi.org/10.1175/JCLI-D-14-00738.s1.

Corresponding author address: Bao Yang, Key Laboratory of Desert and Desertification, Cold and Arid Regions Environmental and Engineering Research Institute, Chinese Academy of Sciences, 320 Donggang West Road, 730000 Lanzhou, China. E-mail: yangbao@lzb.ac.cn
}

et al. 2013; Schmidt et al. 2014). Recently, the PAGES 2k Consortium (2013) reconstructed continental-scale temperature variations over the last one to two millennia, which were used in the Fifth Assessment Report of the Intergovernmental Panel on Climate Change (IPCC AR5) for assessing paleoclimate model simulations on a continental scale (Masson-Delmotte et al. 2013). The geographically heterogeneous availability of temperature proxy data presently poses severe limitations for addressing changes on regional scales, and further improvements of continental-scale reconstructions are thus essential. This is, in particular, the case for Asia, where Cook et al. (2013) used 226 tree-ring chronologies of different length to reconstruct summer [June-August (JJA)] temperature variability since AD 800 as part of the PAGES 2k Consortium (2013). This reconstruction represented temperature variations well $[r>0.5$ with 
the CRU Time Series, version 3.10 (TS3.10), temperature data; University of East Anglia CRU (2013)] over the higher latitudes of Asia (north of $36^{\circ} \mathrm{N}$ ), but unfortunately had little skill $(r<0.2$ with the CRU TS3.10 temperature data) over most of the middle and low latitudes of Asia (south of $\sim 36^{\circ} \mathrm{N}$ ) and especially over the Tibetan Plateau (TP) [see Fig. 11 in Cook et al. (2013)]. One reason for this may be the limited number of temperature-sensitive tree-ring chronologies used in the reconstruction by Cook et al. (2013) from the TP. Another underlying reason could be the spatial heterogeneity of temperature variability over much of Asia, which poses a challenge to large-scale (e.g., continentalto-hemispheric scales) temperature reconstructions using tree-ring chronologies representing local-to-regional-scale temperature variability (Esper et al. 2002; D'Arrigo et al. 2006; Büntgen et al. 2010). An additional challenge for this particular region is the relatively short and often incomplete instrumental temperature records, which makes it difficult to produce robust calibration and validation statistics because of the limited degrees of freedom (You et al. 2008; Liu et al. 2009; Cook et al. 2013).

The TP, with an average elevation exceeding $4000 \mathrm{~m}$ above mean sea level, is the highest and most extensive highland region in the world, and its ecosystems and hydrological cycles are very sensitive to climate changes (Fang et al. 2009; Huang et al. 2011). Improving our understanding of temperature variations over the TP is particularly important because of this region's role in affecting large-scale atmospheric circulations: for example, it affects the strength of the South Asian summer monsoon (SASM) and East Asian summer monsoon (EASM) through changing the land-sea thermal contrast (Li and Yanai 1996; Wu et al. 2012). The eastern TP (ETP) is especially becoming a key area of dendroclimatological research, mainly because of the availability of the long-lived (>500 yr) trees (e.g., Sabina przewalskii Kom.) and particularly well-preserved subfossil and archaeological wood samples in some areas (see, e.g., Bräuning 1994; Zhang et al. 2003; Sheppard et al. 2004; Yang et al. 2014). During the past $15 \mathrm{yr}$, many dendroclimatologists have collected tree-ring width (TRW) samples in high mountainous areas over the ETP and have developed temperature reconstructions covering centuries to several millennia (Shao and Fan 1999; Bräuning and Mantwill 2004; Liang et al. 2008; Zhu et al. 2008, 2011; Fan et al. 2010; Yang et al. 2010b; Li et al. 2012; Deng et al. 2014; He et al. 2014; Wang et al. 2014). These local reconstructions improve our understanding of past temperature variability over the ETP, but, to date, there is still a lack of regional-scale temperature reconstruction with annual resolution focusing on the ETP. Nevertheless, in contrast with those local reconstructions, a regional temperature reconstruction is especially needed to better understand historical temperature changes and their controlling mechanisms over the ETP.

In this work, we developed a regional-scale reconstruction of the ETP summer (JJA) temperature variability over the last millennium (AD 1000-2005) using 12 temperaturesensitive TRW site chronologies of different length. Our new composite reconstruction can be regarded as a complement to the reconstruction efforts of the Past Global Changes (PAGES) Asia 2000 (2k) working group (Cook et al. 2013; PAGES 2k Consortium 2013). We will compare our new reconstruction with estimated solar and volcanic forcing, as well as with index series of the Atlantic multidecadal oscillation (AMO) and the $\mathrm{Pa}$ cific decadal oscillation (PDO) to explore potential factors potentially controlling ETP temperature variability over multidecadal time scales. Additionally, we focus on the differences in the temperature evolution found between our new reconstructions and existing reconstructions for the higher latitudes of East Asia, central-eastern China and the whole of the Northern Hemisphere (NH).

\section{Data and methods}

\section{a. Instrumental and tree-ring data}

The instrumental target data for the reconstruction is based on the CRU TS3.22 $0.5^{\circ} \times 0.5^{\circ}$ gridded monthly temperature dataset covering the period 1901-2013 (Harris et al. 2014; University of East Anglia CRU 2014). Summer mean temperature values over the study region $\left(25^{\circ}-40^{\circ} \mathrm{N}, 85^{\circ}-105^{\circ} \mathrm{E}\right)$ were calculated by taking the arithmetic mean of the months of JJA. Since most of the meteorological station records over the ETP did not start until the late 1950s (You et al. 2008; Liu et al. 2009), we only use the more reliable period after AD 1960 as the calibration period, and we withhold the earlier part of the record AD 1901-59 as the verification period. In this process, the earlier part of instrumental data (AD 1901-59) is used to independently verify the reliability of the reconstruction. The first empirical orthogonal function (EOF1) modes reveal spatial consistency in summer temperature across the ETP during the period AD 1960-2013 for the original instrumental data and the first differences, with an explained variance of $56.2 \%$ and $46.7 \%$, respectively (Fig. S1 in the supplemental material). This high explained variance demonstrates the feasibility of using a number of local temperaturesensitive TRW chronologies to reconstruct regional (the ETP scale) temperature variability as in this study. Additionally, the summer temperature series from the CRU TS3.22 dataset is highly correlated with that from the 12 meteorological stations close to the tree-ring sites 


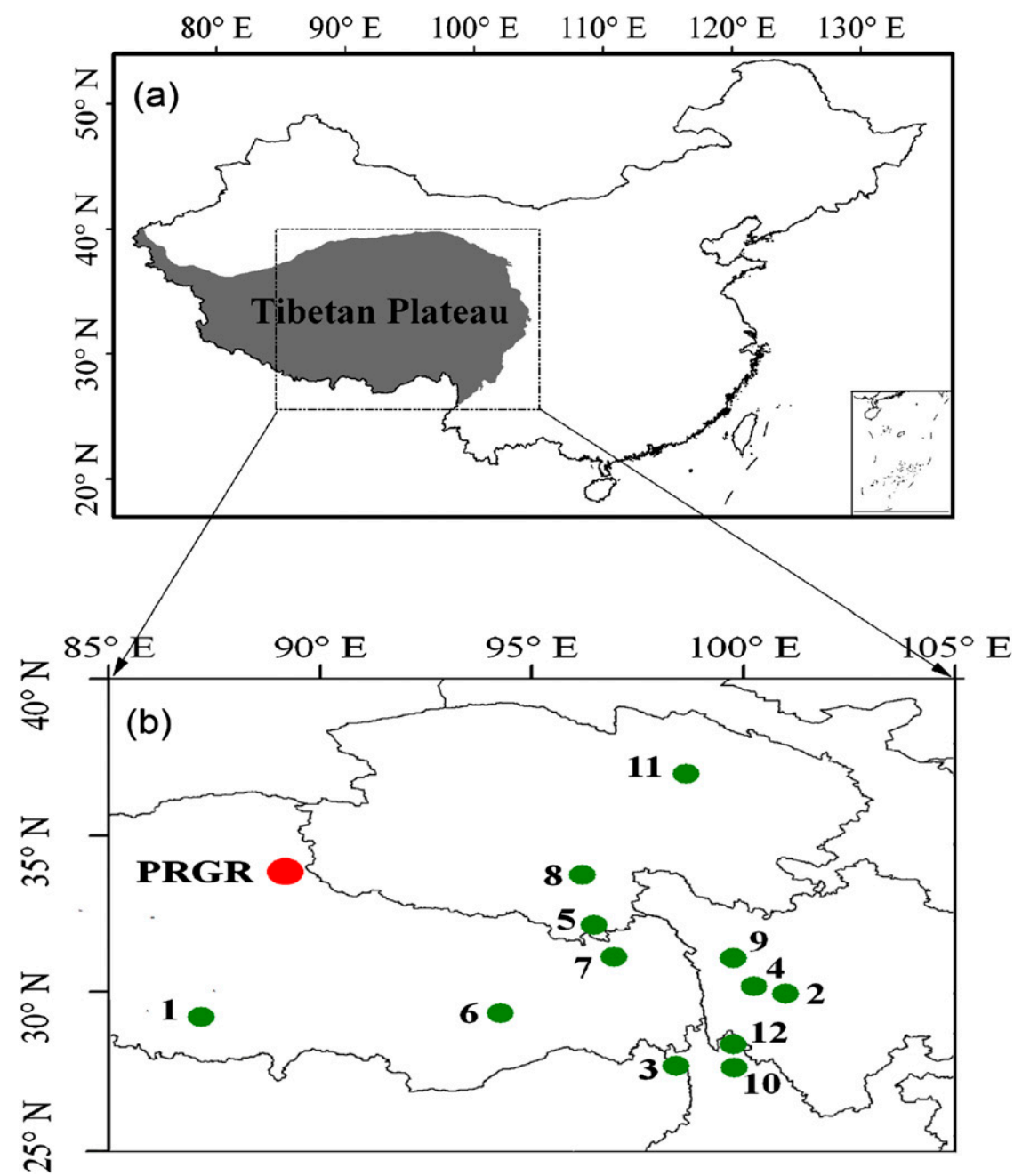

FIG. 1. (a) Location of study region within China. (b) Locations of 12 TRW site chronologies used in our reconstruction and the site of the Puruogangri (PRGR) ice-core $\delta^{18} \mathrm{O}$ record (Thompson et al. 2006). Details of each individual TRW chronology are shown in.

( $r=0.90$ and 0.88 for original data and the first differenced data, respectively; see also Fig. S2 in the supplemental material). In this study, we use the temperature series calculated from the CRU TS3.22 $0.5^{\circ} \times 0.5^{\circ}$ gridded data, rather than that from the 12 stations, to calibrate our reconstruction because we consider that it may be more accurate to represent regional-scale temperature variability, which is the reconstruction target of this study.

A total of 12 temperature-sensitive TRW chronologies, comprising 946 individual TRW samples, were used in this study (Fig. 1 and Table 1). Among these, 10 site chronologies have been previously published and used to reconstruct past summer, winter, or annual mean temperature. Two site chronologies were derived from the International Tree-Ring Data Bank (ITRDB 2014) (Table 1). This tree-ring dataset has only four site chronologies in common (Gongshan, Litang, Shangrila, and Wulan) with the PAGES Asia $2 \mathrm{~K}$ reconstruction (Cook et al. 2013; PAGES 2k Consortium 2013) and adds eight additional temperature-sensitive site chronologies (Table 1). Most of the site chronologies show positive correlations with growing season temperatures between April and September (Fig. 2). All site chronologies show positive correlations with summer (JJA) temperatures, and the highest correlations were found with the averaged JJA temperature $(r=0.28-0.63, p<0.10)$, which we used as our calibration target. Low correlations $(r<0.3)$ with JJA temperature data at some site chronologies may be related to varying seasonal responses [e.g., the Linzhi TRW chronology mainly reflects January-June mean temperature (Yang et al. 2010a)] or varying climatic sensitivities [e.g., the Qumalai TRW chronology mainly reflects January-December minimum temperature (He et al. 2014)]. For the purpose of retaining as much as possible of 


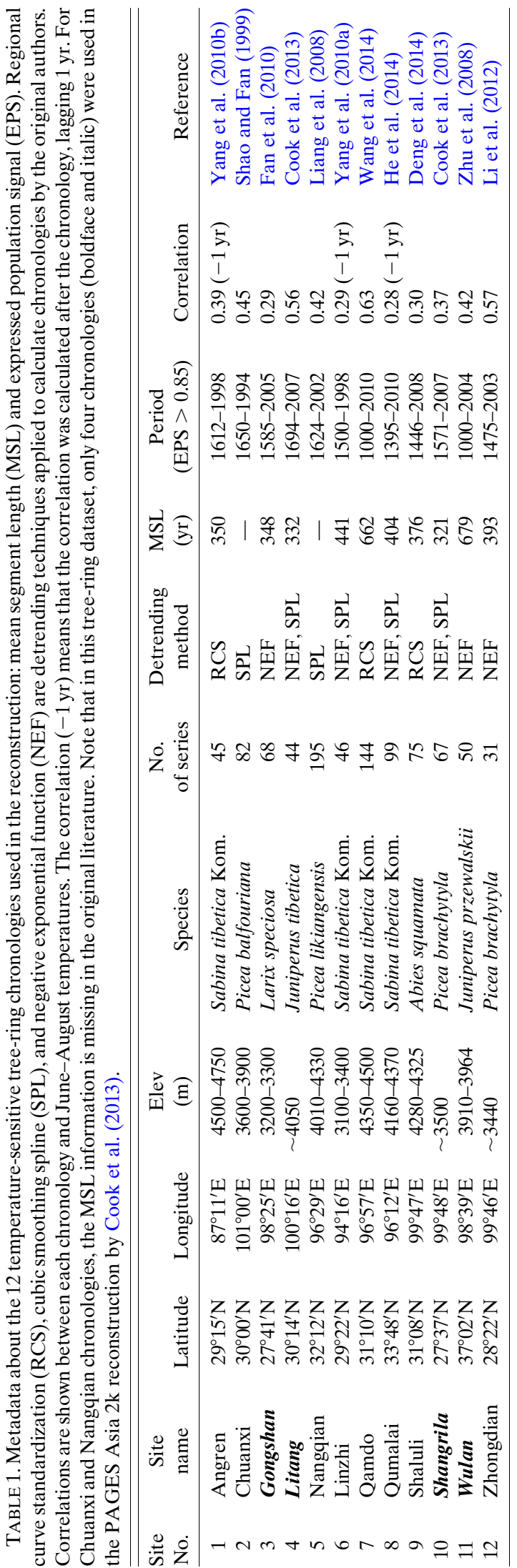

local climate signals, we also included these temperaturesensitive site chronologies in our composite reconstruction, despite their relative low correlations with JJA temperature, but we give them relatively low weights (see reconstruction methods below).

\section{b. Reconstruction methods}

A nested composite-plus-scale (CPS) approach (see, e.g., Hegerl et al. 2007; Jones et al. 2009; PAGES 2k Consortium 2013; Abram et al. 2014) was applied to compute a reconstruction based on 11 different nests, reflecting the decreasing availability of tree-ring chronologies back in time. As described above, the calibration interval (after AD 1960) is rather short, which limits us to producing "forward nests" (Pederson et al. 2013) after AD 1990 by dropping TRW series in recent collections. Considering that no fewer than half (6 out of 12) of our tree-ring records extended to AD 2005, the chronologies that did not reach AD 2005 were extrapolated to this year using the regularized expectation maximization (RegEM) algorithm (Schneider 2001) based on the mutual covariance with the available tree-ring records over the calibration period 1960-2005. After extrapolation, we created 11 "backward nests" following the approach of Pederson et al. (2013). For each nest, the available treering chronologies were first normalized over their common period (AD 1694-2005). Second, the normalized chronologies were each weighted by the strength of the correlation (multiplied by $r$ ) with the instrumental JJA temperature series and, subsequently, combined as a regional tree-ring chronology. In this step, the regionally representative and more strongly summer temperaturesensitive site chronologies were assigned larger weights, whereas the more locally representative and less summer temperature-sensitive chronologies were assigned smaller weights. In other words, the weight of each chronology in the CPS record is based on considering a physical measure of the strength of each record in representing the reconstruction target (Hegerl et al. 2007; Abram et al. 2014). Third, the mean and variance of the regional chronology were scaled to the mean and variance of the instrumental JJA temperature data over the calibration period 19602005 (Esper et al. 2005, 2007; Büntgen et al. 2013). Last, 11 nests are shown relative to their common interval mean (minus the 1694-2005 mean) and then are spliced together to provide the ETP temperature reconstruction over the whole period AD 1000-2005.

For each nest model, the uncertainty was estimated by the root-mean-square error (RMSE). The formula for RMSE is

$$
\mathrm{RMSE}=\sqrt{\frac{1}{n} \sum_{i=1}^{n}\left(y_{i}-\hat{y}_{i}\right)^{2}},
$$




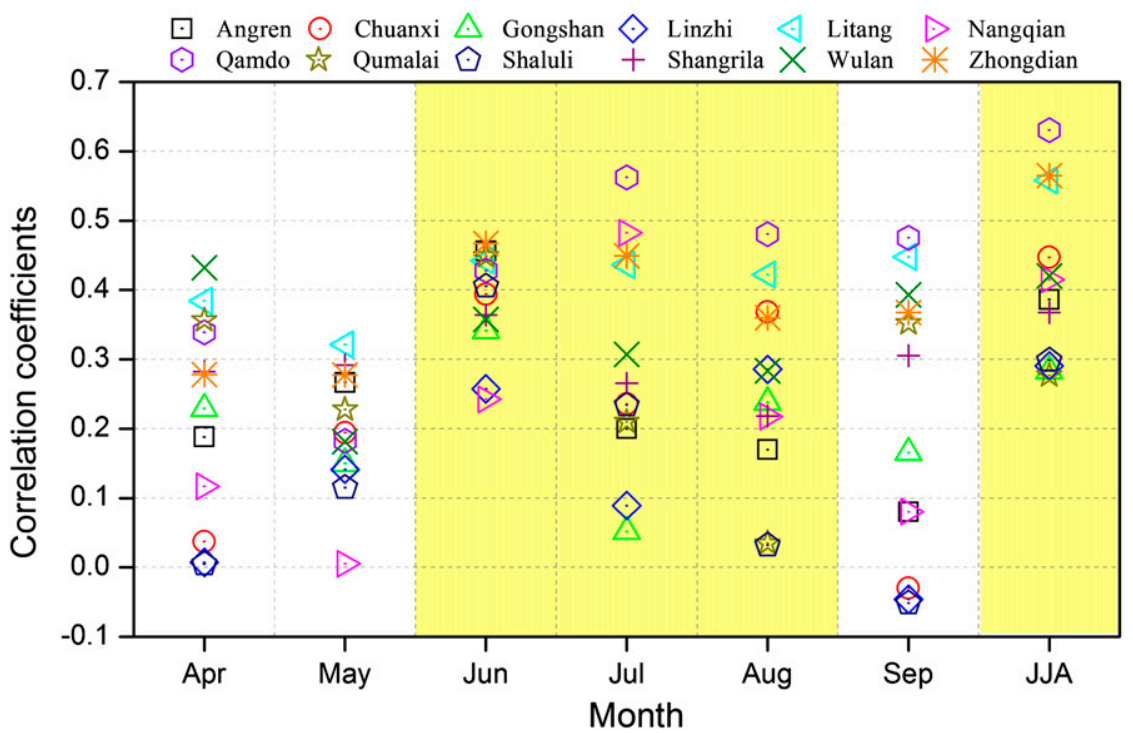

FIG. 2. Correlation of monthly temperature means from the CRU TS3.22 $0.5^{\circ} \times 0.5^{\circ}$ gridded dataset (Harris et al. 2014; University of East Anglia CRU 2014) with the 12 site chronologies computed over their common interval. Note that correlations for the three chronologies (Angren, Linzhi, and Qumalai) were calculated after lagging the temperature $1 \mathrm{yr}$ because of higher correlation with temperature in the previous year than in the current year.

where $y_{i}$ and $\hat{y}_{i}$ are the actual and estimated data in year $i$ of the calibration period, and $n$ is the number of years during the calibration period.

Uncertainties in the form of \pm 1 RMSE were added to the reconstructed values as the uncertainty ranges for each nest. The final uncertainty ranges for the full reconstruction were produced by splicing the uncertainty ranges in each nest. The reduction of error (RE) and coefficient of efficiency (CE) statistics were also calculated to verify each reconstruction nest (Fritts 1976). The RE and CE measures shared variance between the actual and reconstructed series, and a positive value for either of them indicates that the reconstruction has some predictive skill (Cook et al. 1999).

\section{c. Sensitivity tests}

We made a number of sensitivity tests to assess the robustness of our reconstruction by producing alternative reconstructions using different methods, standardized intervals, and calibration datasets (Fig. 3; Figs. S4 and S5 in the supplemental material):

1) Applying the same method as described above, but without using RegEM extrapolation of those records ending prior to AD 2005 (Fig. 3a and Fig. S5a).

2) Standardizing all site chronologies over the calibration interval (AD 1960-2005) instead of over their common period (AD 1694-2005) (Fig. 3b and Fig. S5b).
3) Producing a reconstruction not weighted by the correlation to JJA temperature record, and assuming that each site chronology has the same contribution to this reconstruction (Fig. 3c and Fig. S5c).

4) Calibrating the reconstruction to the HadCRUT4 (Morice et al. 2012; Met Office Hadley Centre and University of East Anglia CRU 2014) and the GISTEMP (Hansen et al. 2010; National Aeronautics and Space Administration 2014) dataset, respectively, instead of to the CRU TS3.22 temperature dataset (Fig. 3d and Fig. S5d).

5) Applying a weighted CPS method, but without nesting and based only on the variable length of contributing chronologies (Fig. 4).

Finally, all reconstructions were expressed as anomalies with respect to the full length of the reconstruction (e.g., the AD 1000-2005 mean). Comparisons of the sensitivity reconstructions with our final reconstruction are shown in Fig. 3 (30-yr low-pass filtered, AD 1000-2005), Fig. S5 (annual data, AD 1000-2005), and Fig. S4 (annual data, AD 1960-2005).

\section{d. Spectral and wavelet analyses}

A multitaper method (MTM) of spectral analysis (Mann and Lees 1996) was performed to identify major periodicities present in the full range of our reconstruction. The statistical confidence level was tested against a red noise background (Mann and Lees 1996). Only the periodicities at multidecadal time scales that are 


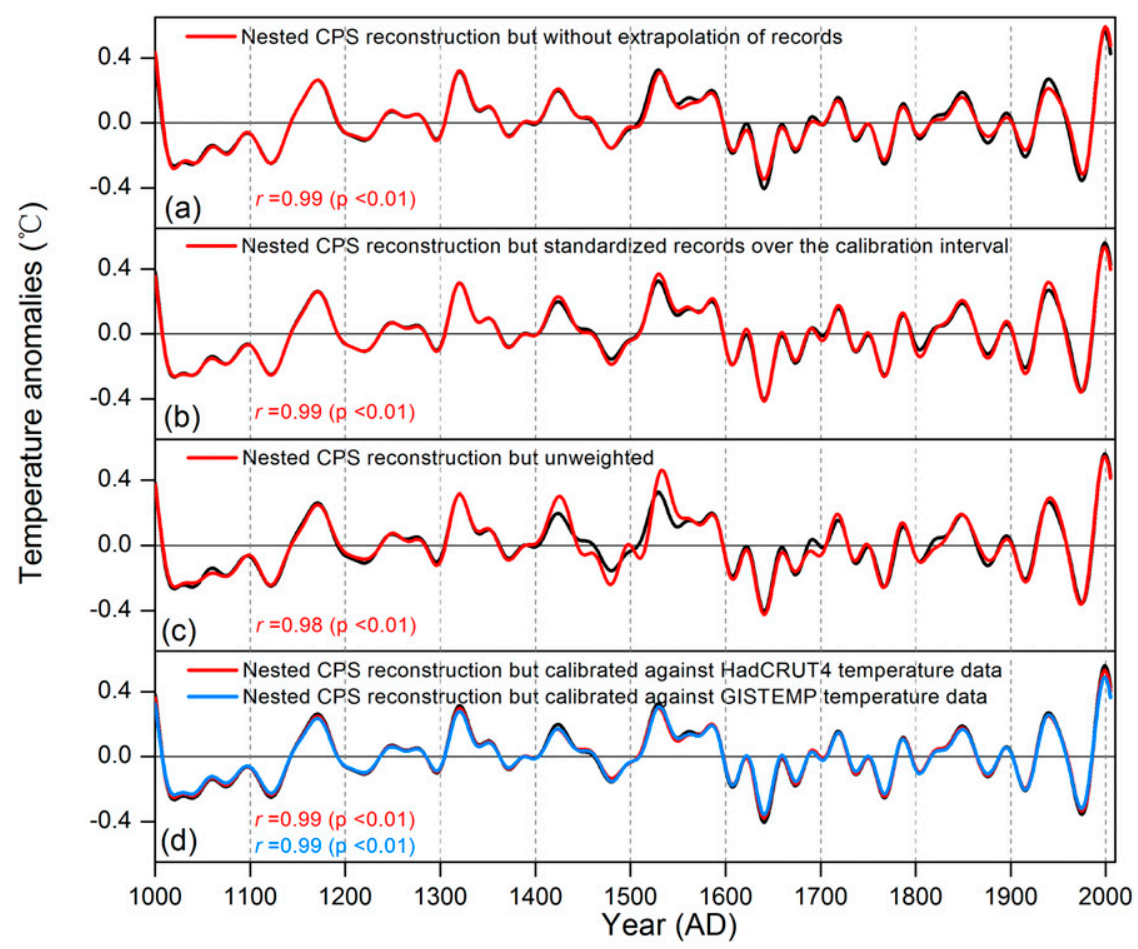

FIG. 3. Comparison of our reconstruction (black) with (from top to bottom) five alternative reconstructions produced with (a) no extrapolation of the records (red), (b) different standardized intervals of records (red), (c) unweighted method (red), and (d) different calibration data (red and blue). The curves show the 30-yr low-pass filtered reconstructions with respect to the period AD 1000-2005. The correlation coefficients between the final reconstruction and alternative reconstructions are shown in each figure. Since there are strong autocorrelations in the low-pass filtered series, the degrees of freedom were adjusted to account for the autocorrelation in the filtered series, as described by Bretherton et al. (1999), when assessing significance of the correlation.

significant at the $95 \%$ confidence level are discussed in detail in this study. In addition, a cross-wavelet analysis (Torrence and Compo 1998) was employed to determine common power and relative phases of our reconstruction and the estimated total solar irradiance (TSI; Steinhilber et al. 2009), as well as the reconstructed AMO index (Mann et al. 2009) in the time frequency domain. In this analysis, the Morlet wavelet was used with $w_{0}=6$ and the statistical significance was tested at the $95 \%$ confidence level against a red noise background (Torrence and Compo 1998).

\section{Results and discussion}

\section{a. Assessing the robustness of the reconstructions}

A number of alternative reconstructions were performed as sensitivity tests, and all matched well with the instrumental JJA temperature records, with a significant $(p<0.01)$ correlation of $0.65-0.71$ for the original data and $0.55-0.68$ for the first differences (Fig. S4). Among them, the alternative reconstruction produced by standardizing all records over the calibration interval has the highest correlation $(r=0.71)$ with the instrumental record; whereas the alternative reconstruction calibrated with GISTEMP data shows the lowest correlation $(r=$ $0.65)$ with the instrumental record. The comparison between the instrumental record and the reconstructed time series also shows that all of these reconstructions capture instrumental temperature variability well in both the lowand high-frequency domains (Fig. S4).

Figure 3 shows a comparison with these sensitivity reconstructions. These reconstructions show the same temperature change characteristics both in low-frequency (Fig. 3) and high-frequency domains (Fig. S5), with significant $(p<0.01)$ correlations of $0.98-0.99$ for the 30-yr low-pass filtered data and 0.97-0.99 for the annual data over the reconstruction period (AD 1000-2005). Comparison shows only slight differences in the period $\mathrm{AD}$ 1450-1550 between reconstructions produced by using or not using a weighted method (Fig. 3c). The reconstruction produced by using an unweighted method 


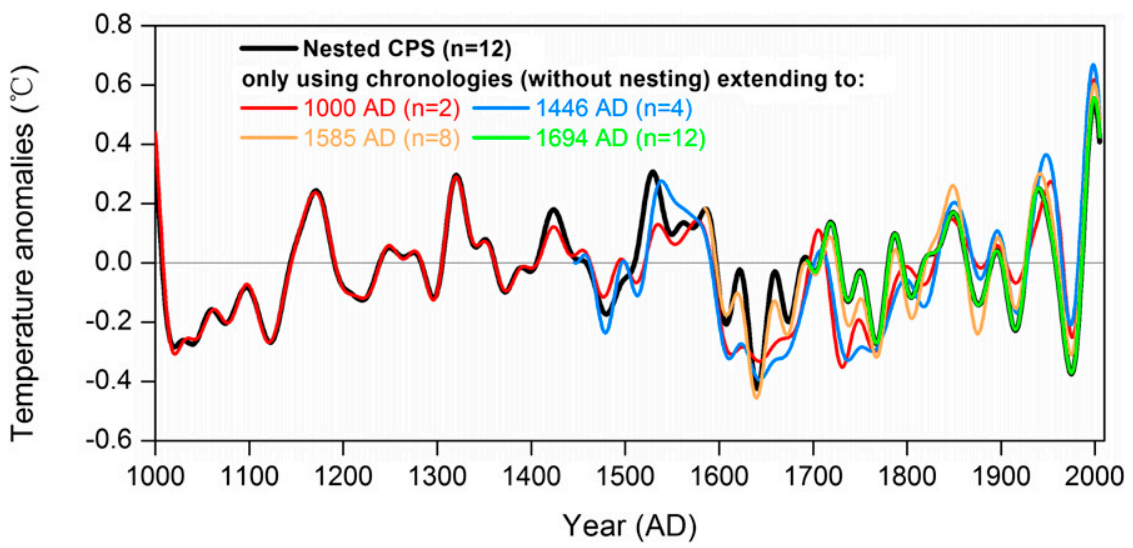

FIG. 4. Comparison of temperature reconstructions produced with or without using a nesting method. The curves show the 30-yr low-pass filtered reconstructions with respect to their common period AD 1694-2005.

shows a colder AD 1450-1500 and a warmer AD 1500-50 than that produced by using a weighted method. This may be related to the fact that the site chronologies [e.g., Qumalai (He et al. 2014) and Shaluli (Deng et al. 2014)] with low correlations to the JJA temperature record show more notable characteristics of the cold AD 1450-1500 and the warm AD 1500-50 than the other records (see also Fig. S3). In the unweighted reconstruction, each site chronology has the same contribution to the reconstruction, whereas in the weighted reconstruction, the contribution of each site chronology has been weighted using its correlation with the JJA temperature record. The inference above is also supported by the comparison among the reconstructions produced without nesting (Fig. 4). Figure 4 shows that when increasing the number of site chronologies to four (adding the Qumalai and the Shaluli chronologies) it will show a colder AD 1450-1500 and a warmer AD 1500-50 than that only using two site chronologies (Qamdo and Wulan). However, the comparison between reconstructions with or without using the nesting method broadly shows no substantial differences between them at decadal-to-centennial time scales (Fig. 4). Additionally, if three chronologies (Linzhi, Qumalai, and Gongshan) with low correlations $(r<0.30)$ with JJA temperature series were excluded, there will be no significant change in reconstruction results (see Fig. S6 in the supplemental material). Overall, these combined results from the sensitivity tests suggest that our reconstruction is robust and not particularly sensitive to specific methods, standardized intervals, or calibration datasets.

\section{b. Reconstruction modeling and spatial representation}

The reconstructed and instrumental JJA temperature data show a correlation of $0.70(p<0.01)$ over the calibration period AD 1960-2005. They fitted well not only at interannual time scales but also at decadal and longer time scales (Fig. 5a). Although both the reconstructed and instrumental data indicate a general warming trend during recent decades, after AD 2000, a warming hiatus and even a cooling trend is a dominant feature, consistent with the widely reported global warming hiatus (Kosaka and Xie 2013; Meehl et al. 2014). It should be noted that, although very few instrumental data are available before AD 1960 over the ETP, the reconstruction also matches the CRU instrumental temperature data $(r=0.58, p<0.01)$ over the period 1901-59 well. Here, this interval was also chosen as the verification period to assess the skill of the reconstruction models. The correlation coefficients range from 0.62 to 0.70 for 11 nests and are all significant at the 0.01 level, which indicates a high consistency between reconstructed and instrumental temperature variations (Fig. 5c). Besides, both positive RE and CE values for all nests indicate that the reconstruction model has some predictive skill (Fritts 1976; Cook et al. 1995), although verification RE and CE both drop below 0.1 over the period AD 1000-1475, when less than 4 chronologies are available (Fig. 5d). The RMSE values, ranging from $0.29^{\circ}$ to $0.34^{\circ} \mathrm{C}$, generally decrease with an increasing number of chronologies. They are also greater than the standard deviation of the final reconstruction itself $\left(0.21^{\circ} \mathrm{C}\right)$.

The spatial correlation pattern shows a close relationship between the reconstruction and CRU temperature data over western China (west of $105^{\circ} \mathrm{E}$ ), with correlations exceeding $0.60(p<0.05)$ across most of the area of interest (Fig. 6). However, the first differenced data show very different spatial patterns, with significant correlations only over the ETP between $\sim 90^{\circ}$ and $105^{\circ} \mathrm{E}$ and south of $\sim 40^{\circ} \mathrm{N}$ (Fig. 6). This suggests that most of 

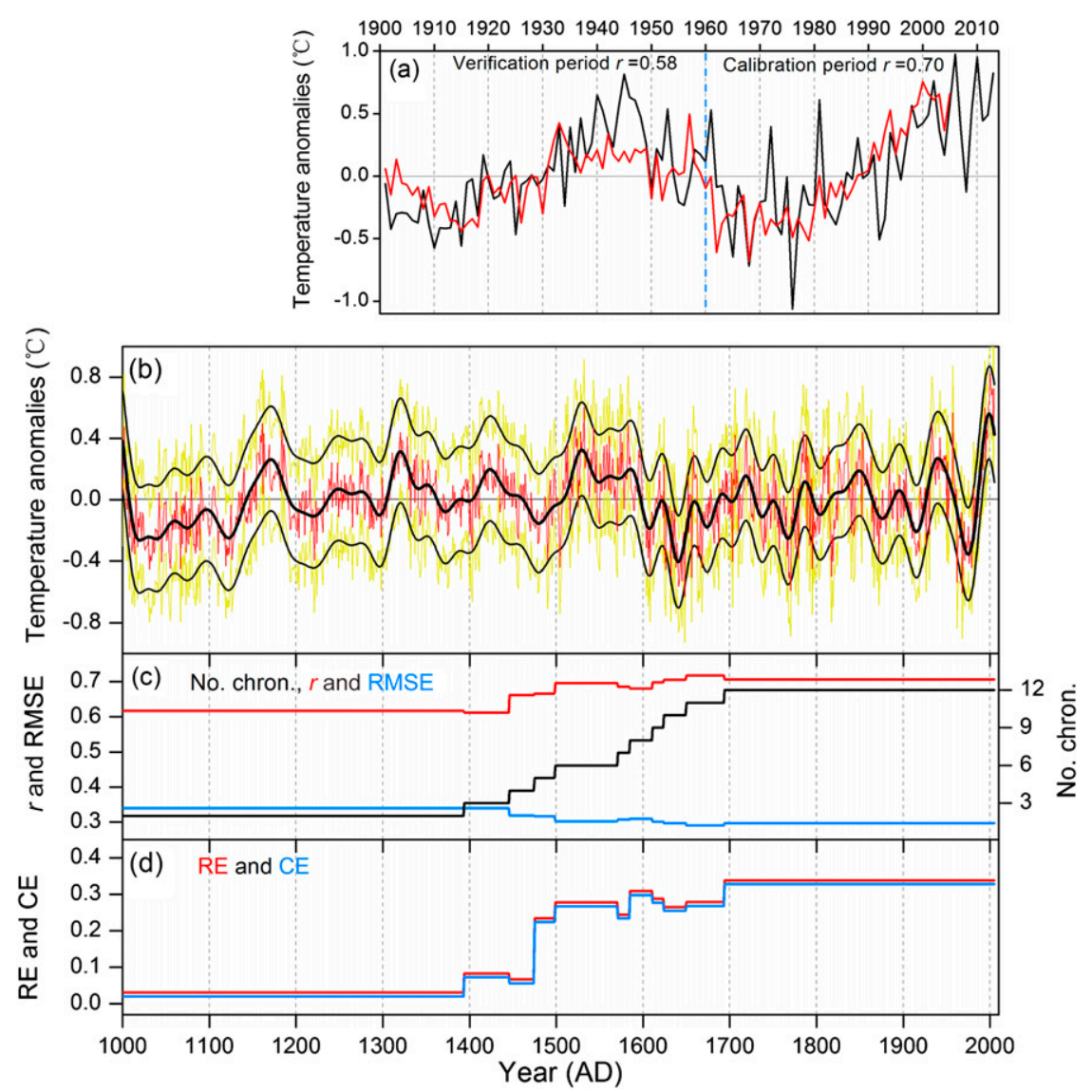

FIG. 5. (a) Comparison between instrumental (black) and reconstructed (red) temperature anomalies. (b) Reconstructed temperature anomalies (red), the uncertainty estimates (yellow), and their 30-yr low-pass filters (black) during the period AD 1000-2005 relative to mean over the full reconstruction period. (c),(d) The statistics of the number of tree-ring chronologies (No. chron.), correlation coefficient (r), RMSE, RE, and CE for each nest.

significant correlations, except that in the ETP, revealed by the original data are relatively sensitive to the presence of trends or autocorrelations in the data. Thus, we consider that the most reliable representation of the reconstruction is only limited to the ETP, which is also covered with most of the tree-ring chronologies we used. It should also be noted here, however, that the reconstruction will be more uncertain and have poorer spatial coverage back in time, because of the uneven distribution of tree-ring sites and the decreasing number of chronologies.

\section{c. Temperature variability over the last millennium}

The 1006-yr-long reconstruction shows subcentennial cold episodes in much of the eleventh, seventeenth, and eighteenth centuries, and warm episodes in the sixteenth, nineteenth, and twentieth centuries (Fig. 5b). The cold interval in the eleventh century had been observed in various proxy records over the TP (Yang et al.
2003) and was associated with glacier advances over the southern TP (Yang et al. 2008a; Solomina et al. 2015), but it is quite opposite to the warm conditions prevailing in other temperature reconstructions from China (Yang et al. 2002; Shi et al. 2012; Ge et al. 2013) and in most of the NH at this time (Mann et al. 2009; Christiansen and Ljungqvist 2012; Ljungqvist et al. 2012; PAGES 2k Consortium 2013; Shi et al. 2013). Furthermore, this cold interval was concurrent with relative wetness, although some other cold intervals (e.g., AD 1450-1520, 16001700 , and 1750-1830) were generally related to dry conditions in the north and south TP (Grießinger et al. 2011; He et al. 2013; Yang et al. 2014; Fig. S7 in the supplemental material). The results from the $100-\mathrm{yr}$ running correlation analysis indicate that temperature and precipitation changes exhibit an in-phase relationship during the past millennium and that this relationship was more robust in the north TP than in the south TP (Fig. S7). Although weak, such positive correlations 
(a)

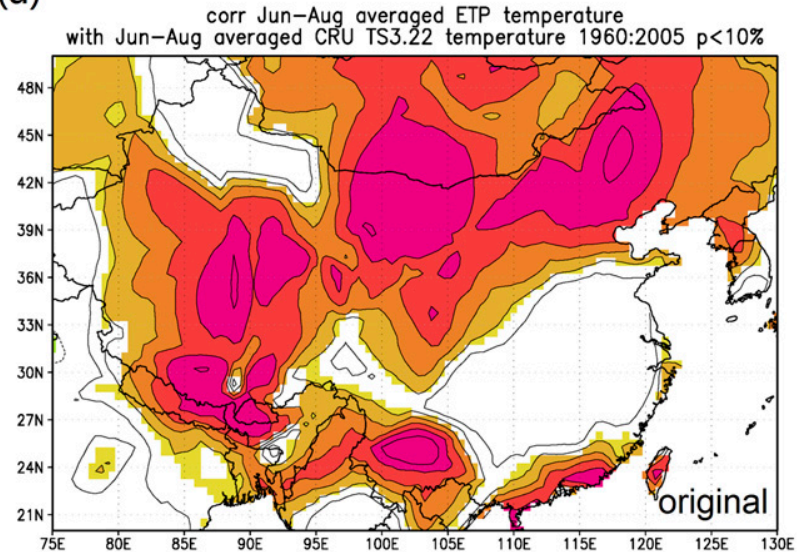

(b)

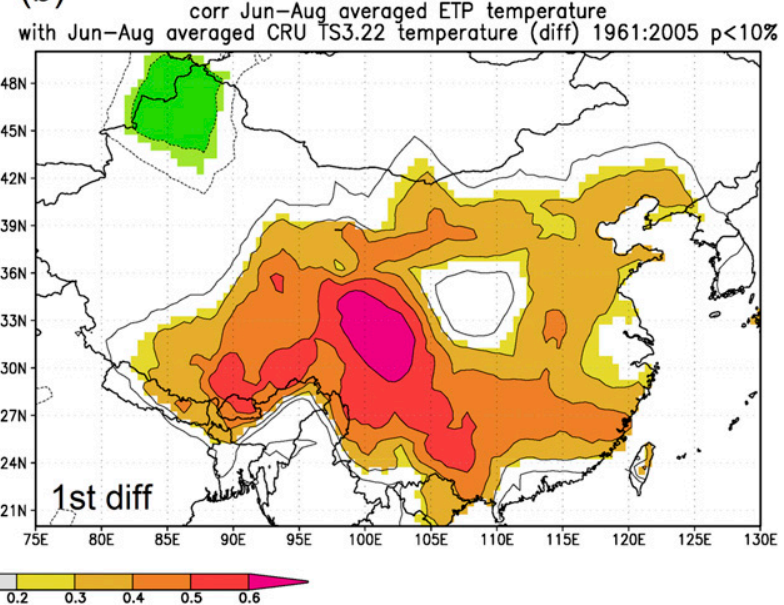

FIG. 6. (a) Spatial correlations of the reconstruction with CRU TS3.22 $0.5^{\circ} \times 0.5^{\circ}$ gridded temperatures over the period $1960-2005$. (b) As in (a), but for the first differenced data. The filled map was produced using the KNMI Climate Explorer (Trouet and van Oldenborgh 2013).

between the ETP temperature and the south TP precipitation may support the relationship between the TP summer temperature and the SASM intensity over the past millennium. However, it should be noted that such a relationship may have changed in recent decades, when the ETP is warming, but both the SASM (Wu 2005) and EASM (Li et al. 2010) are also weakening. Recent analyses by Sun et al. (2010) and Dai et al. (2013) show that the weakening of the SASM and EASM during recent decades is mainly caused by the weakening of the land-sea thermal contrast in the mid-upper troposphere because of tropical sea surface warming. These results imply that, under the condition of global warming, the land-sea thermal contrast in the midupper troposphere may play a more important role than that in the near-surface in influencing SASM and EASM intensity.

The recent decade (AD 1996-2005) was likely the warmest 10 -yr interval, with an average temperature $0.62^{\circ} \pm 0.30^{\circ} \mathrm{C}$ higher than the $1000-2005$ mean. However, when taking the calibration uncertainties ( \pm 1 RMSE) into consideration, it is not statistically significant that recent summer warmth over the ETP is unprecedented over the last millennium, a conclusion that is consistent with the tree-ring-based temperature reconstruction for East Asia by Cook et al. (2013) and other temperature reconstructions from China (e.g., Yang et al. 2002; Shi et al. 2012; Ge et al. 2013).

Although numerous terrestrial low-resolution sediment archives are available from the ETP, we choose to compare our reconstruction with the Puruogangri ice-core $\delta^{18} \mathrm{O}$ record (Thompson et al. 2006) from the central TP, since it can be accurately calibrated to the instrumental
JJA temperature data (Yang et al. 2008b, 2009). The two records show similar behavior on multidecadal time scales, with generally colder conditions during much of the eleventh, seventeenth, and eighteenth centuries, and warmer conditions during the sixteenth and twentieth centuries (Fig. 7). Some slight differences are also seen in the two records. Our reconstruction shows warmer conditions during the first half of the fourteenth and fifteenth centuries, while the $\delta^{18} \mathrm{O}$ record suggests colder conditions. It should be questioned whether these differences between our tree-ring-based temperature reconstruction and ice-core $\delta^{18} \mathrm{O}$ series can be resulting from the fact that low-frequency climate signals is sometimes underestimated in tree-ring width chronology, which is widely known as "segment length curse" (Cook et al. 1995). The maximum wavelength of climate information extracted by the tree-ring chronology usually cannot exceed the length of one-third of the mean segment length (MSL) of tree-ring series when traditional detrending methods are used (Cook et al. 1995). In this study, the 12 chronologies we used have the MSL of 321-679 yr, with a mean value of $\sim 430 \mathrm{yr}$. This suggests that our composite reconstruction may have some difficulty in reconstructing temperature variability at multicentury-or-longer time scales. However, the differences between our tree-ring-based reconstruction and the ice-core $\delta^{18} \mathrm{O}$ record almost appeared at time scales no longer than a century (Fig. 7). Thus, we infer the segment length curse in the tree-ring chronology may not be important enough as a factor to cause such differences. In contrast, we consider that these differences might arise from the complexity of climate signals recorded by the glacier $\delta^{18} \mathrm{O}$ (for a review, see Yao et al. 2013), the dating 


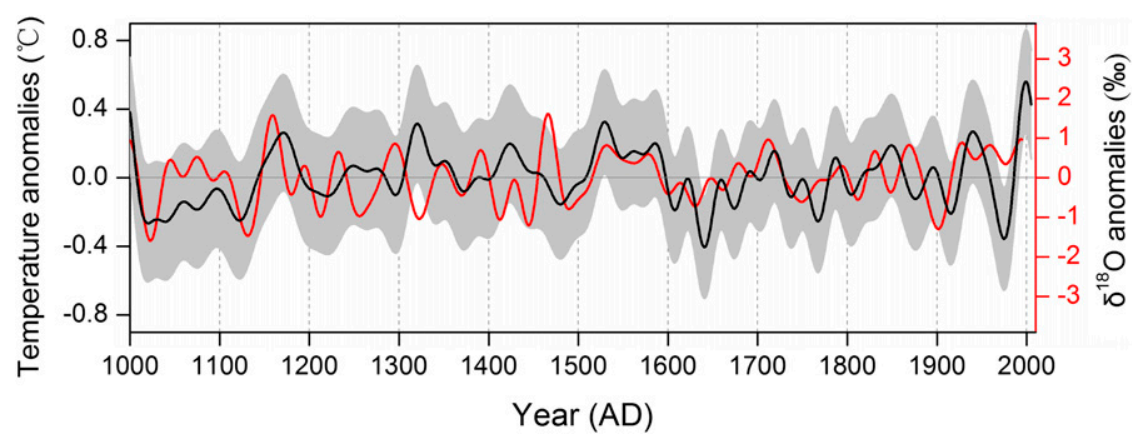

FIG. 7. Comparison of the reconstructed temperature anomalies (black), as well as the uncertainty ranges (gray shading) with the Puruogangri ice-core $\delta^{18} \mathrm{O}$ record (red). Note that only the 30-yr low-pass filtered values are shown.

error of the Puruogangri ice core $( \pm 20-30 \mathrm{yr}$ in the time interval AD 1000-1600), or the influence of local climate variations on the ice-core $\delta^{18} \mathrm{O}$ (Thompson et al. 2006; Yao et al. 2006).

A spectral analysis, using the MTM of Mann and Lees (1996), shows dominant periodicities of around $\sim(2-3)$, $\sim(50-55), 75,120$, and $150 \mathrm{yr}$ in our reconstruction (Fig. 8). The periodicities of 120 and $150 \mathrm{yr}$ may tentatively be related to solar activity (Steinhilber et al. 2009; Gray et al. 2010). The periodicities of $\sim(50-55)$ and $75 \mathrm{yr}$ may relate to internal ocean-atmosphere oscillations, in particular the AMO (Enfield et al. 2001) and the PDO (Mantua and Hare 2002). A comparison of the reconstructed temperature with estimated changes in total solar irradiance (Steinhilber et al. 2009) suggests a weak and unstable relationship at multidecadal time scales (Fig. 9). The Oort (circa AD 1010-50) and Maunder (circa AD 1645-1715) solar minima periods were generally associated with temperature depressions. On the other hand, there was a lack of response to solar forcing during the Wolf (circa AD 1280-1350), the Spörer (circa AD 1420/50-1550/70) and the Dalton (circa AD 1790-1830) minima periods, as well as during some other periods of multidecadal length (yellow bars in Fig. 9). A cross-wavelet and bandpass filtering analysis further supports the above results and indicates a weak relationship over the last millennium and even an out-of-phase relationship in the earlier $800 \mathrm{yr}$ between the TSI and the ETP temperature series (see Fig. S8 in the supplemental material). On the other hand, as shown in Fig. 9, this lack of response to solar forcing does not appear to be linked to large volcanic eruptions (Gao et al. 2008) (Fig. 9). Consequently, we suppose that multidecadal variations of summer temperature across the ETP may mainly be controlled by factors other than a direct response to solar and/or volcanic forcing, such as internal ocean-atmosphere oscillations related in particular to the AMO or PDO. Here, however, caution is still needed to consider the influence of solar and volcanic forcings; after all, simple correlations and comparisons do not, by themselves, demonstrate causation. To test our hypothesis, we calculated the correlations of our reconstruction with the instrumental summer AMO index (Enfield et al. 2001) and summer PDO index (Mantua and Hare 2002). The reconstructed temperature significantly correlates $(r=0.34, p<0.01)$ with the AMO index during the period AD 1856-2005, whereas it does not at all significantly correlate $(r=0.07)$ with the PDO index. After applying a 10-yr low-pass filter, the correlation with the AMO index increases to 0.60, but it remains weak with the PDO index $(r=0.22)$. A simple visual comparison also reveals a closer relationship with the AMO than with the PDO during the instrumental period (Fig. S9 in the supplemental material). A similar finding was also recently reported in a study of decadal variations of global averaged temperature (Muller et al. 2013).

To focus more closely on the $\sim(50-55)$ - and 75 -yr periodicities seen in our ETP reconstruction, we compared

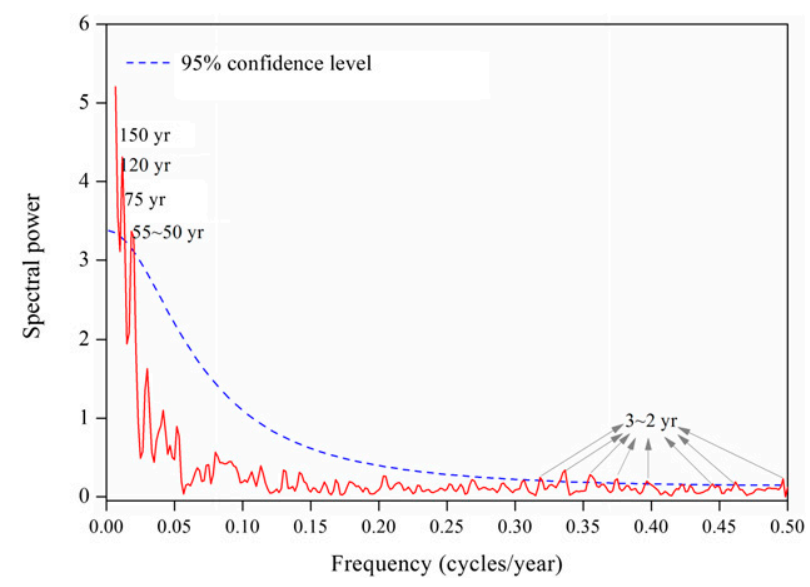

FIG. 8. Multitaper spectral analysis (Mann and Lees 1996) of the reconstruction over the period 1000-2005. 


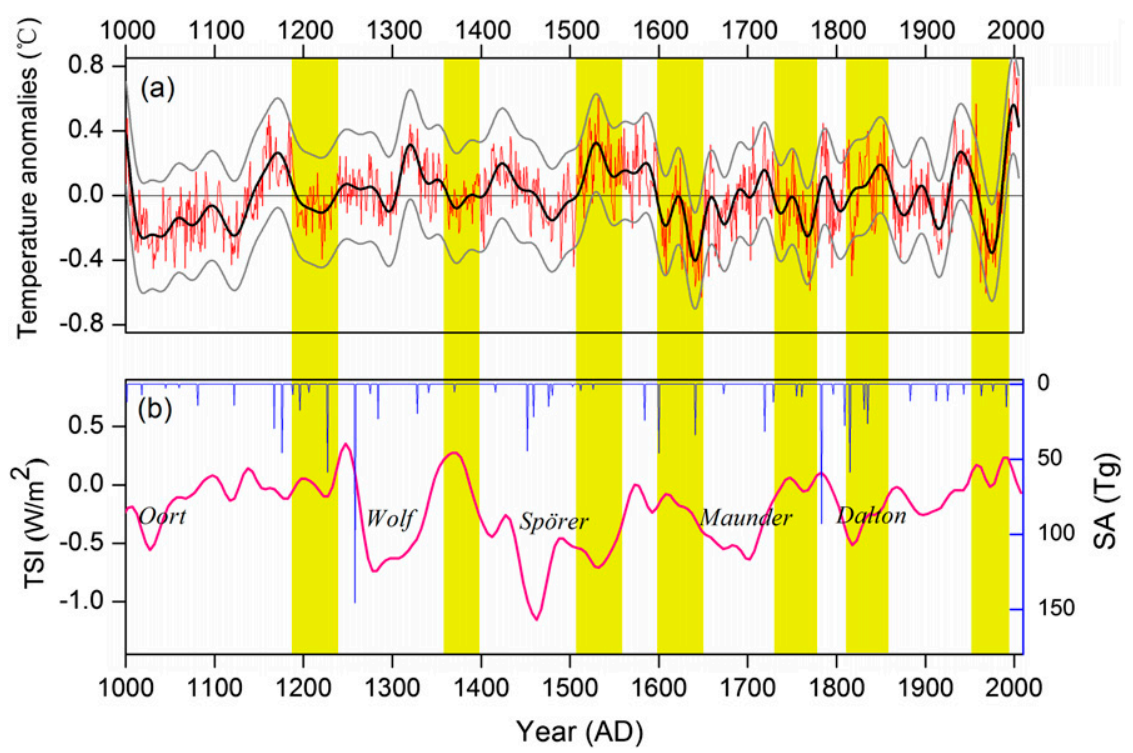

FIG. 9. (a) Reconstructed summer temperature anomalies (red) and the corresponding 30-yr low-pass filtered values (black), as well as the uncertainty estimates (gray). (b) The estimated TSI (Steinhilber et al. 2009) (red) and the NH stratospheric sulfate aerosol (SA) (Gao et al. 2008) (blue). The yellow bars highlight a lack of response of temperature variability to solar forcing at multidecadal time scales.

our reconstruction with the reconstructed AMO index by Mann et al. (2009) in the periodicities of $\sim(50-55)$ and $75 \mathrm{yr}$ (Fig. 10). The result shows nearly the same characteristic in variability in the two series at the periodicities of $\sim(50-55)$ and $75 \mathrm{yr}$, with a stable in-phase relationship during the whole past millennium (Figs. 10a,b). Furthermore, this in-phase relationship is also prominent in the combination of $\sim(50-55)$ - and 75 -yr periodicities (Fig. 10c) and in the bandpass filtered 50-75-yr component (Fig. 10d). Additionally, the cross-wavelet analysis further supports a general in-phase relationship at a wider time scale of 40-90 yr during the last millennium (see Fig. S10 in the supplemental material). These results suggest a close link between the AMO and temperature variations in the ETP at multidecadal time scales. This is also consistent with recent findings, showing an important role of the AMO in explaining multidecadal temperature variability in other parts of China during the last millennium (Wang et al. 2013) and northeast Asia (Wang et al. 2011).

A close link between the AMO and temperature variability over the ETP has also been observed in instrumental observations (Feng and $\mathrm{Hu}$ 2008) and in coupled climate model simulations ( $\mathrm{Li}$ et al. 2008; Wang et al. 2009; Luo et al. 2011). Feng and Hu (2008) analyzed the difference of composite summer surface temperature and SLP between AMO warm and cold phases and found that summer temperature is warmer over the Eurasian continent in AMO warm phases than cold phases, and the warming is especially significant in the central and eastern TP and then spreads into its adjacent regions. Such connection of temperature anomalies between the North Atlantic and East Asia can also be reproduced in the model simulations ( $\mathrm{Li}$ et al. 2008; Wang et al. 2009). Using atmospheric general circulation models, Li et al. (2008) and Luo et al. (2011) conducted diagnostic simulations of warming North Atlantic SSTs and found a propagating Rossby wave train in the middle and upper troposphere extending from the Atlantic across Asia, indicating that high Atlantic SST can directly warm the middle or upper troposphere of the Asian continent. Additionally, evidence from both proxy records and climate model simulations has suggested an important role of the AMO in influencing summer monsoon rainfall over East Asia by affecting the temperature over the TP and changing the meridional temperature gradient between the East Asian continent and the tropical Indian Ocean (Feng and $\mathrm{Hu}$ 2008; Li et al. 2008). In this study, our results provide evidence to support modeling and observational results that have suggested that the AMO can influence temperature over the ETP (Li and Bates 2007; Feng and $\mathrm{Hu}$ 2008; Li et al. 2008) and thus change the landsea thermal contrast between the East Asian continent and the tropical Indian Ocean (Li and Yanai 1996; Wu et al. 2012). To a certain extent, our results can extend the existence of the above possible dynamic mechanisms back through at least the whole past millennium. 
(a)

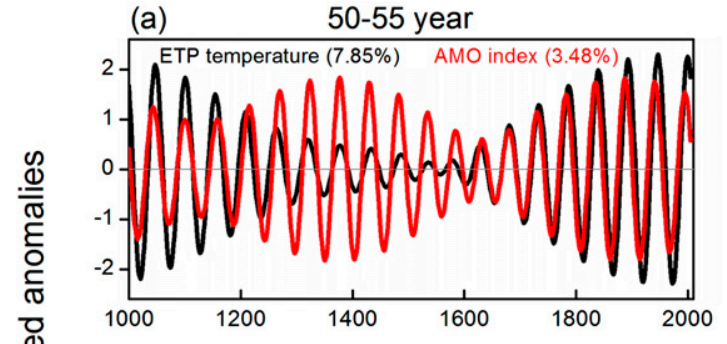

(c) $\quad 50-55$ year +75 year

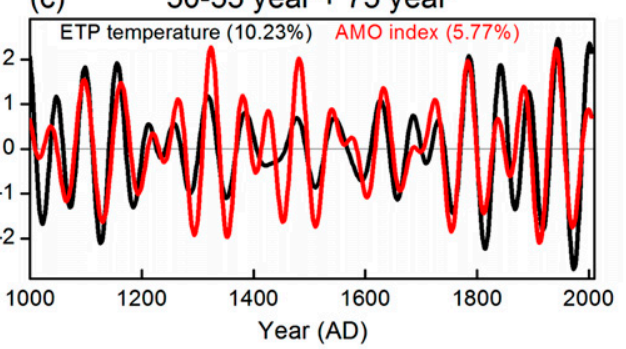

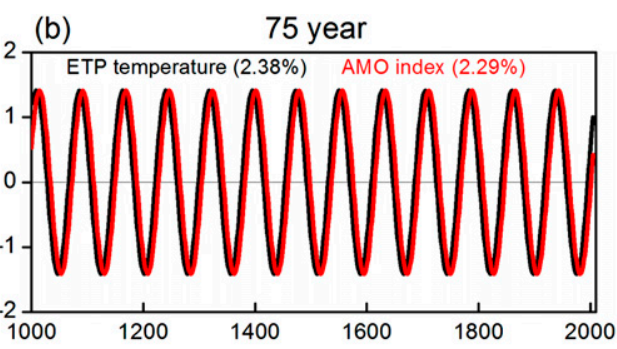

(d)

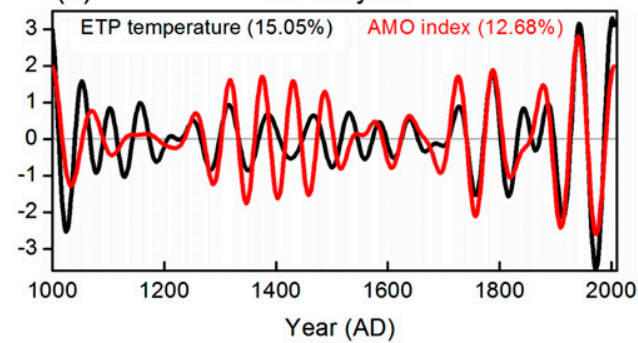

FIG. 10. Comparison between our reconstruction (black) and AMO index (Mann et al. 2009) (red) in (a) (5055 )-yr, (b) 75-yr, (c) the combination of the $\sim(50-55)$ - and 75-yr, and (d) 50-75-yr periodicities. The variations in these periodicities were extracted using the bandpass filtering method. The values in the parentheses describe the explained variance of the bandpass filtered series relative to the original series (unfiltered data).

Finally, we compared the ETP-scale summer temperature reconstruction with the tree-ring-based summer temperature reconstruction for East Asia (considering that the most reliable region explained by the reconstruction is limited to north of $36^{\circ} \mathrm{N}$, here tentatively regarded as a temperature reconstruction for the higher latitudes of East Asia) (Cook et al. 2013) and documentary-based winter season temperature reconstruction from centraleast China (Ge et al. 2010, 2013). Additionally, three millennia-long temperature reconstructions for the $\mathrm{NH}$ by Mann et al. (2009) and Shi et al. (2013) and the extratropical $\left(90^{\circ}-60^{\circ} \mathrm{N}\right) \mathrm{NH}$ temperature reconstruction by Christiansen and Ljungqvist (2012), were also added for a large-scale comparison. As shown in Fig. 11, the multiproxy reconstructions for the $\mathrm{NH}$ and the documentarybased reconstruction for central-east China show obvious multicentennial-scale variations, such as higher temperatures during the Medieval Warm Period [MWP; AD $\sim(1000-1300)]$ and cold conditions during the Little Ice Age [LIA; AD (1600-1900)]. In contrast, our tree-ringbased reconstruction does not show a warmer MWP and colder LIA, which may be partly related to the segment length curse in tree-ring chronology (Cook et al. 1995); as we have discussed earlier, our reconstruction cannot retrieve multicentennial variation trends. We then mainly focus on similarities and differences among these temperature records at subcentennial and multidecadal time scales.

Overall, the comparison shows that the differences are more significant than the similarities between our reconstruction and the others at subcentennial scales (Fig. 11). To focus on the similarities, there were common cold periods in the second half of the fifteenth and seventeenth centuries, and a similar recent warm period. To focus on the differences, it is evident that the eleventh century was a cold state in the ETP but was warm in the high latitudes of East Asia and central-eastern China, as well as across most of the NH. The second half of the twelfth century and the first half of the fourteenth century were two very warm episodes in the higher latitudes of East Asia and over the ETP but were cold ones in centraleastern China and also across much of the NH. The nineteenth century was cold in the high latitudes of East Asia, central-eastern China, and the NH mean, but relatively warm over the ETP. In summary, these comparisons show that the warm nineteenth century and the cold eleventh century in the ETP are somewhat unique and reflect some regional differences of temperature changes across East Asia. These regional differences may truly reflect spatially diverse temperature changes but could also partly be a result of different reconstruction methodologies, varying seasonal responses, or varying climatic sensitivities between different proxy records. Additionally, the reduced sample replication in the earlier part of our reconstruction may be another potential contribution to the differences. These regional differences in temperature variations highlight the need to build additional millennium-long, temperature-sensitive tree-ring chronologies from the ETP and other parts of East Asia. 


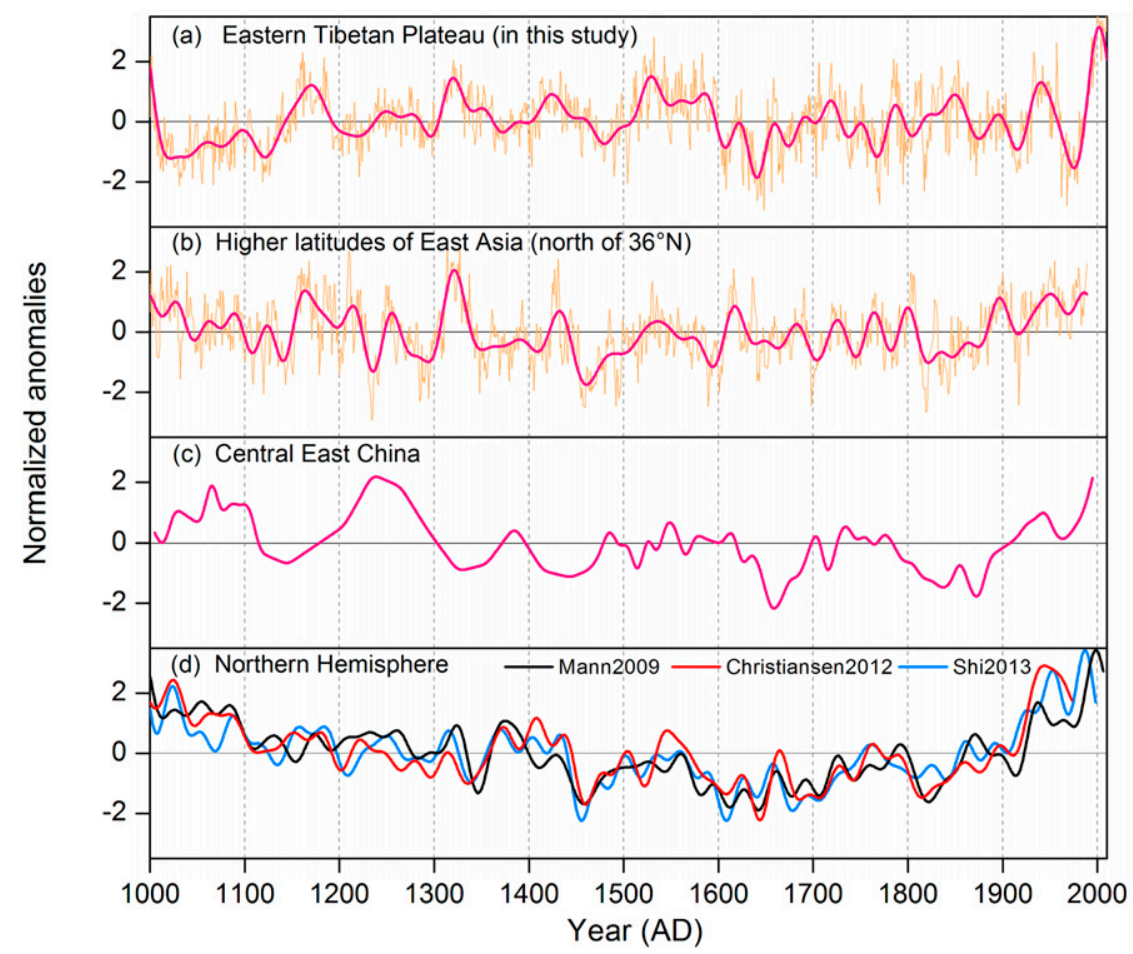

FIG. 11. Comparison of (a) the summer temperature reconstruction for the ETP with (b) the tree-ring-width-based summer temperature reconstruction from the higher latitudes of East Asia (Cook et al. 2013), (c) documentary-based winter temperature proxy from central-east China (Ge et al. 2010, 2013), and (d) multiproxy temperature reconstructions from the NH by Mann et al. (2009) in black, the Shi et al. (2013) in blue, and the extratropical $\left(90^{\circ}-30^{\circ} \mathrm{N}\right)$ reconstruction by Christiansen and Ljungqvist (2012) in red. In (a) and (b), for two tree-ring-based reconstructions, annual temperatures are shown in orange and the 30-yr low-pass filtered values are expressed in red. In (c), the documentarybased winter season temperature reconstruction with 10 -yr resolution is shown in red. In (d), for the $\mathrm{NH}$ temperature reconstructions, only the 30-yr low-pass filtered data are shown.

\section{Conclusions}

Using 12 temperature-sensitive TRW chronologies of different length, combined and calibrated through a nested CPS approach, this study presents the first millennium-length regional summer (JJA) temperature composite reconstruction with annual resolution for the ETP. Among the 12 site chronologies, only 2 site chronologies cover the full millennium. Nevertheless, our sensitivity tests indicate that the reconstruction based on only the 2 site chronologies that cover the full millennium still have some skill. A number of sensitivity tests indicated that our composite reconstruction is relatively robust, regardless of reconstruction method, standardized intervals, and choice of calibration dataset. The reconstructed JJA temperatures are characterized by subcentennial cold episodes during much of the eleventh, seventeenth and eighteenth centuries and warm episodes occurring during much of the sixteenth, nineteenth, and twentieth centuries. The 10-yr interval 19962005 was the warmest decade in the context of the past millennium, although this result is not statistically significant when taking the estimated uncertainty range into consideration. Furthermore, our reconstruction shows only a weak relationship with direct solar forcing at multidecadal time scales but reveals a robust in-phase relationship with the AMO, suggesting that the AMO plays a major role in the summer temperature variability over the ETP at multidecadal time scales. Additionally, comparisons with temperature reconstructions from the higher latitudes of East Asia, as well as from centraleastern China, show that the temperature evolution over the ETP is somewhat different over the past millennium. Admittedly, the earlier part of our reconstruction may have somewhat more uncertainty in reflecting a regional temperature in the ETP because of the reduced sample 
replication before AD 1600. To reduce such uncertainty, this study highlights a need to further increase the number of millennium-length chronologies in the ETP.

Acknowledgments. The authors want to express their gratitude to Profs. Xuemei Shao, Qibin Zhang, Xiaohua Gou, and Eryuan Liang and Drs. Haifeng Zhu, Zexin Fan, Zongshan $\mathrm{Li}$, and Yang Deng for providing their tree-ring chronologies. We also wish to thank the editor and the three anonymous reviewers for their valuable comments and suggestions. This study was jointly funded by the CAS Strategic Priority Research Program Grant XDA05080801, the National Natural Science Foundation of China (NSFC) (Grants 41325008 and 41272189), the CAS/SAFEA International Partnership Program for Creative Research Teams, and the CAS Interdisciplinary Innovation Team project (Grant 29Y329B91).

\section{REFERENCES}

Abram, N. J., R. Mulvaney, F. Vimeux, S. J. Phipps, J. Turner, and M. H. England, 2014: Evolution of the Southern Annular Mode during the past millennium. Nat. Climate Change, 4, 564-569, doi:10.1038/nclimate2235.

Braconnot, P., S. P. Harrison, M. Kageyama, P. J. Bartlein, V. Masson-Delmotte, A. Abe-Ouchi, B. Otto-Bliesner, and Y. Zhao, 2012: Evaluation of climate models using palaeoclimatic data. Nat. Climate Change, 2, 417-424, doi:10.1038/ nclimate1456.

Bräuning, A., 1994: Dendrochronology for the last 1400 years in eastern Tibet. GeoJournal, 34, 75-95, doi:10.1007/BF00813972. , and B. Mantwill, 2004: Summer temperature and summer monsoon history on the Tibetan plateau during the last 400 years recorded by tree rings. Geophys. Res. Lett., 31, L24205, doi:10.1029/2004GL020793.

Bretherton, C. S., M. Widmann, V. P. Dymnikov, J. M. Wallace, and L. Bladé, 1999: The effective number of spatial degrees of freedom of a time-varying field. J. Climate, 12, 1990-2009, doi:10.1175/1520-0442(1999)012<1990:TENOSD>2.0.CO;2.

Büntgen, U., J. Franke, D. Frank, R. Wilson, F. González-Rouco, and J. Esper, 2010: Assessing the spatial signature of European climate reconstructions. Climate Res., 41, 125-130, doi:10.3354/ cr00848.

- - T. Tyncl, C. Ginzler, D. S. Jacks, J. Esper, W. Tegel, K.-U. Heussner, and J. Kyncl, 2013: Filling the Eastern European gap in millennium-long temperature reconstructions. Proc. Natl. Acad. Sci. USA, 110, 1773-1778, doi:10.1073/ pnas.1211485110.

Christiansen, B., and F. C. Ljungqvist, 2012: The extra-tropical Northern Hemisphere temperature in the last two millennia: Reconstructions of low-frequency variability. Climate Past, 8, 765-786, doi:10.5194/cp-8-765-2012.

Coats, S., J. E. Smerdon, R. Seager, B. I. Cook, and J. GonzálezRouco, 2013: Megadroughts in southwestern North America in ECHO-G millennial simulations and their comparison to proxy drought reconstructions. J. Climate, 26, 7635-7649, doi:10.1175/JCLI-D-12-00603.1.

Cook, E. R., K. R. Briffa, D. M. Meko, D. A. Graybill, and G. Funkhouser, 1995: The segment length curse in long tree-ring chronology development for palaeoclimatic studies. Holocene, 5, 229-237, doi:10.1177/095968369500500211.

_, D. M. Meko, D. W. Stahle, and M. K. Cleaveland, 1999: Drought reconstructions for the continental United States. J. Climate, 12,1145-1162, doi:10.1175/1520-0442(1999)012<1145: DRFTCU $>2.0 . \mathrm{CO} ; 2$.

— P. J. Krusic, K. J. Anchukaitis, B. M. Buckley, T. Nakatsuka, and M. Sano, 2013: Tree-ring reconstructed summer temperature anomalies for temperate East Asia since $800 \mathrm{CE}$. Climate Dyn., 41, 2957-2972, doi:10.1007/s00382-012-1611-x.

Dai, A., H. Li, Y. Sun, L.-C. Hong, LinHo, C. Chou, and T. Zhou, 2013: The relative roles of upper and lower tropospheric thermal contrasts and tropical influences in driving Asian summer monsoons. J. Geophys. Res. Atmos., 118, 7024-7045, doi:10.1002/jgrd.50565.

D'Arrigo, R., R. Wilson, and G. Jacoby, 2006: On the long-term context for late twentieth century warming. J. Geophys. Res., 111, D03103, doi:10.1029/2005JD006352.

Deng, Y., X. Gou, L. Gao, T. Yang, and M. Yang, 2014: Earlysummer temperature variations over the past $563 \mathrm{yr}$ inferred from tree rings in the Shaluli Mountains, southeastern Tibet Plateau. Quat. Res., 81, 513-519, doi:10.1016/ j.yqres.2013.08.002.

Enfield, D. B., A. M. Mestas-Nuñez, and P. J. Trimble, 2001: The Atlantic Multidecadal Oscillation and its relation to rainfall and river flows in the continental U.S. Geophys. Res. Lett., 28, 2077-2080, doi:10.1029/2000GL012745.

Esper, J., E. R. Cook, and F. H. Schweingruber, 2002: Lowfrequency signals in long tree-ring chronologies for reconstructing past temperature variability. Science, 295, 2250-2253, doi:10.1126/science. 1066208.

_ D. Frank, R. Wilson, and K. R. Briffa, 2005: Effect of scaling and regression on reconstructed temperature amplitude for the past millennium. Geophys. Res. Lett., 32, L07711, doi:10.1029/ 2004GL021236.

- _ - U U. Büntgen, A. Verstege, J. Luterbacher, and E. Xoplaki, 2007: Long-term drought severity variations in Morocco. Geophys. Res. Lett., 34, L17702, doi:10.1029/2007GL030844.

Fan, Z.-X., A. Bräuning, Q.-H. Tian, B. Yang, and K.-F. Cao, 2010: Tree ring recorded May-August temperature variations since A.D. 1585 in the Gaoligong Mountains, southeastern Tibetan Plateau. Palaeogeogr. Palaeoclimatol. Palaeoecol., 296, 94 102, doi:10.1016/j.palaeo.2010.06.017.

Fang, K., X. Gou, F. Chen, J. Peng, R. D’Arrigo, W. Wright, and M. H. Li, 2009: Response of regional tree-line forests to climate change: Evidence from the northeastern Tibetan Plateau. Trees, 23, 1321-1329, doi:10.1007/s00468-009-0373-5.

Feng, S., and Q. Hu, 2008: How the North Atlantic Multidecadal Oscillation may have influenced the Indian summer monsoon during the past two millennia. Geophys. Res. Lett., 35, L01707, doi:10.1029/2007GL032484.

Fernández-Donado, L., and Coauthors, 2013: Large-scale temperature response to external forcing in simulations and reconstructions of the last millennium. Climate Past, 9, 393-421, doi:10.5194/cp-9-393-2013.

Fritts, H. C., 1976: Tree Rings and Climate. Academic Press, 567 pp.

Gao, C., A. Robock, and C. Ammann, 2008: Volcanic forcing of climate over the past 1500 years: An improved ice core-based index for climate models. J. Geophys. Res., 113, D23111, doi:10.1029/2008JD010239.

Ge, Q., J. Y. Zheng, Z. X. Hao, X. M. Shao, W.-C. Wang, and J. Luterbacher, 2010: Temperature variation through 2000 years in China: An uncertainty analysis of reconstruction and 
regional difference. Geophys. Res. Lett., 37, L03703, doi:10.1029/ 2009 GL041281.

— Z. Hao, J. Zheng, and X. Shao, 2013: Temperature changes of the past $2000 \mathrm{yr}$ in China and comparison with the Northern Hemisphere. Climate Past, 9, 1153-1160, doi:10.5194/cp-9-1153-2013.

Gray, L. J., and Coauthors, 2010: Solar influences on climate. Rev. Geophys., 48, RG4001, doi:10.1029/2009RG000282.

Grießinger, J., A. Bräuning, G. Helle, A. Thomas, and G. Schleser, 2011: Late Holocene Asian summer monsoon variability reflected by $\delta^{18} \mathrm{O}$ in tree-rings from Tibetan junipers. Geophys. Res. Lett., 38, L03701, doi:10.1029/2010GL045988.

Hansen, J., R. Ruedy, M. Sato, and K. Lo, 2010: Global surface temperature change. Rev. Geophys., 48, RG4004, doi:10.1029/ 2010RG000345.

Harris, I., P. Jones, T. Osborn, and D. Lister, 2014: Updated highresolution grids of monthly climatic observations-The CRU TS3.10 dataset. Int. J. Climatol., 34, 623-642, doi:10.1002/joc.3711.

He, M., B. Yang, A. Brauning, J. Wang, and Z. Wang, 2013: Treering derived millennial precipitation record for the southcentral Tibetan Plateau and its possible driving mechanism. Holocene, 23, 36-45, doi:10.1177/0959683612450198.

—,- , and N. Datsenko, 2014: A six hundred-year annual minimum temperature history for the central Tibetan Plateau derived from tree-ring width series. Climate Dyn., 43, 641-655, doi:10.1007/s00382-013-1882-x.

Hegerl, G., T. Crowley, M. Allen, W. T. Hyde, H. N. Pollack, J. Smerdon, and E. Zorita, 2007: Detection of human influence on a new, validated 1500-year temperature reconstruction. J. Climate, 20, 650-666, doi:10.1175/JCLI4011.1.

Huang, L., J. Liu, Q. Shao, and R. Liu, 2011: Changing inland lakes responding to climate warming in Northeastern Tibetan Plateau. Climatic Change, 109, 479-502, doi:10.1007/s10584-011-0032-x.

ITRDB, 2014: Tree ring database. International Tree-Ring Data Bank, accessed 10 April 2014. [Available online at http://www. ncdc.noaa.gov/paleo/treering.html.]

Jones, P. D., and Coauthors, 2009: High-resolution palaeoclimatology of the last millennium: A review of current status and future prospects. Holocene, 19, 3-49, doi:10.1177/ 0959683608098952.

Kosaka, Y., and S. P. Xie, 2013: Recent global-warming hiatus tied to equatorial Pacific surface cooling. Nature, 501, 403-407, doi:10.1038/nature12534.

Li, C. Y., and M. Yanai, 1996: The onset and interannual variability of the Asian summer monsoon in relation to landsea thermal contrast. J. Climate, 9, 358-375, doi:10.1175/ 1520-0442(1996)009<0358:TOAIVO>2.0.CO;2.

Li, H., A. Dai, T. Zhou, and J. Lu, 2010: Responses of East Asian summer monsoon to historical SST and atmospheric forcing during 1950-2000. Climate Dyn., 34, 501-514, doi:10.1007/ s00382-008-0482-7.

Li, S., and G. T. Bates, 2007: Influence of the Atlantic Multidecadal Oscillation on the winter climate of East China. Adv. Atmos. Sci., 24, 126-135, doi:10.1007/s00376-007-0126-6.

_ J. Perlwitz, X. Quan, and M. P. Hoerling, 2008: Modelling the influence of North Atlantic multidecadal warmth on the Indian summer rainfall. Geophys. Res. Lett., 35, L05804, doi:10.1029/2007GL032901.

Li, Z., Q. Zhang, and K. Ma, 2012: Tree-ring reconstruction of summer temperature for A.D. 1475-2003 in the central Hengduan Mountains, Northwestern Yunnan, China. Climatic Change, 110, 455-467, doi:10.1007/s10584-011-0111-z.

Liang, E., X. Shao, and N. Qin, 2008: Tree-ring based summer temperature reconstruction for the source region of the
Yangtze River on the Tibetan Plateau. Global Planet. Change, 61, 313-320, doi:10.1016/j.gloplacha.2007.10.008.

Liu, X., Z. Cheng, L. Yan, and Z.-Y. Yin, 2009: Elevation dependency of recent and future minimum surface air temperature trends in the Tibetan Plateau and its surroundings. Global Planet. Change, 68, 164-174, doi:10.1016/j.gloplacha.2009.03.017.

Ljungqvist, F. C., P. J. Krusic, G. Brattström, and H. S. Sundqvist, 2012: Northern Hemisphere temperature patterns in the last 12 centuries. Climate Past, 8, 227-249, doi:10.5194/cp-8-227-2012.

Luo, F., S. Li, and T. Furevik, 2011: The connection between the Atlantic Multidecadal Oscillation and the Indian Summer Monsoon in Bergen Climate Model Version 2.0. J. Geophys. Res., 116, D19117, doi:10.1029/2011JD015848.

Mann, M., and J. Lees, 1996: Robust estimation of background noise and signal detection in climatic time series. Climatic Change, 33, 409-445, doi:10.1007/BF00142586.

— gins of the Little Ice Age and Medieval climate anomaly. Science, 326, 1256-1260, doi:10.1126/science.1177303.

Mantua, N. J., and S. R. Hare, 2002: The Pacific Decadal Oscillation. J. Oceanogr., 58, 35-44, doi:10.1023/ A:1015820616384.

Masson-Delmotte, V., and Coauthors, 2013: Information from paleoclimate archives. Climate Change 2013: The Physical Science Basis, T. F. Stocker et al., Eds., Cambridge University Press, 383-464. [Available online at http://www.ipcc.ch/pdf/ assessment-report/ar5/wg1/WG1AR5_Chapter05_FINAL.pdf.]

Meehl, G. A., H. Teng, and J. M. Arblaster, 2014: Climate model simulations of the observed early-2000s hiatus of global warming. Nat. Climate Change, 4, 898-902, doi:10.1038/nclimate2357.

Met Office Hadley Centre and University of East Anglia CRU, 2014: Hadley Centre/CRU gridded surface temperature data set version 4 (HadCRUT4). Met Office Hadley Centre observations datasets, accessed 5 May 2014. [Available online at http://www.metoffice.gov.uk/hadobs/hadcrut4/data/current/ download.html.]

Morice, C. P., J. J. Kennedy, N. A. Rayner, and P. D. Jones, 2012: Quantifying uncertainties in global and regional temperature change using an ensemble of observational estimates: The HadCRUT4 data set. J. Geophys. Res., 117, D08101, doi:10.1029/ 2011JD017187.

Muller, R. A., and Coauthors, 2013: Decadal variations in the global atmospheric land temperatures. J. Geophys. Res., 118, 5280-5286, doi:10.1002/jgrd.50458.

National Aeronautics and Space Administration, 2014: NASA Goddard Institute for Space Studies (GISS) Surface Temperature (GISSTEMP): Surface air temperature, $250 \mathrm{~km}$ smoothing data of month-by-month variation. Accessed 5 May 2014. [Available online at http://data.giss.nasa.gov/gistemp/.]

PAGES 2k Consortium, 2013: Continental-scale temperature variability during the past two millennia. Nature Geosci., 6, 339-346, doi:10.1038/ngeo1797.

Pederson, N., A. R. Bell, E. R. Cook, U. Lall, N. Devineni, R. Seager, K. Eggleston, and K. P. Vranes, 2013: Is an epic pluvial masking the water insecurity of the greater New York City region. J. Climate, 26, 1339-1354, doi:10.1175/JCLI-D-11-00723.1.

Phipps, S. J., and Coauthors, 2013: Paleoclimate data-model comparison and the role of climate forcings over the past 1500 years. J. Climate, 26, 6915-6936, doi:10.1175/JCLI-D-12-00108.1.

Schmidt, G. A., and Coauthors, 2014: Using palaeo-climate comparisons to constrain future projections in CMIP5. Climate Past, 10, 221-250, doi:10.5194/cp-10-221-2014. 
Schneider, T., 2001: Analysis of incomplete climate data: Estimation of mean values and covariance matrices and imputation of missing values. J. Climate, 14, 853-871, doi:10.1175/ 1520-0442(2001)014<0853:AOICDE > 2.0.CO;2.

Shao, X., and J. Fan, 1999: Past climate on west Sichuan Plateau as reconstructed from ring-widths of dragon spruce (in Chinese). Quat. Sci., 1, 81-89.

Sheppard, P. R., P. E. Tarasov, L. J. Graumlich, K.-U. Heussner, M. Wagner, H. Osterle, and L. G. Thompson, 2004: Annual precipitation since $515 \mathrm{BC}$ reconstructed from living and fossil juniper growth of northeastern Qinghai Province, China. Climate Dyn., 23, 869-881, doi:10.1007/s00382-004-0473-2.

Shi, F., B. Yang, and L. Gunten, 2012: Preliminary multiproxy surface air temperature field reconstruction for China over the past millennium. Sci. China, 55D, 2058-2067, doi:10.1007/ s11430-012-4374-7.

_ — - A. Mairesse, L. von Gunten, J. Li, A. Bräuning, F. Yang, and X. Xiao, 2013: Northern Hemisphere temperature reconstruction during the last millennium using multiple annual proxies. Climate Res., 56, 231-244, doi:10.3354/cr01156.

Solomina, O. N., and Coauthors, 2015: Holocene glacier fluctuations. Quat. Sci. Rev., 111, 9-34, doi:10.1016/ j.quascirev.2014.11.018.

Steinhilber, F., J. Beer, and C. Fröhlich, 2009: Total solar irradiance during the Holocene. Geophys. Res. Lett., 36, L19704, doi:10.1029/2009GL040142.

Sun, Y., Y. Ding, and A. Dai, 2010: Changing links between South Asian summer monsoon circulation and tropospheric land-sea thermal contrasts under a warming scenario. Geophys. Res. Lett., 37, L02704, doi:10.1029/2009GL041662.

Thompson, L. G., and Coauthors, 2006: Abrupt tropical climate change: Past and present. Proc. Natl. Acad. Sci. USA, 103, 10 536-10 543, doi:10.1073/pnas.0603900103.

Torrence, C., and G. P. Compo, 1998: A practical guide to wavelet analysis. Bull. Amer. Meteor. Soc., 79, 61-78, doi:10.1175/ 1520-0477(1998)079<0061:APGTWA > 2.0.CO;2.

Trouet, V., and G. J. van Oldenborgh, 2013: KNMI Climate Explorer: A web-based research tool for high-resolution paleoclimatology. Tree-Ring Res., 69, 3-13, doi:10.3959/1536-1098-69.1.3.

University of East Anglia CRU, 2013: CRU TS3.10: Climatic Research Unit (CRU) Time-Series (TS) version 3.10 of highresolution gridded data of month-by-month variation in climate (Jan. 1901-Dec. 2009). NCAS British Atmospheric Data Centre, accessed 5 May 2014. [Available online at http://catalogue. ceda.ac.uk/uuid/ac3e6be017970639a9278e64d3fd5508.]

, 2014: CRU TS3.22: Climatic Research Unit (CRU) TimeSeries (TS) version 3.22 of high-resolution gridded data of monthby-month variation in climate (Jan. 1901-Dec. 2013). NCAS British Atmospheric Data Centre, accessed 10 September 2014, doi:10.5285/18BE23F8-D252-482D-8AF9-5D6A2D40990C.

Wang, J., B. Yang, F. C. Ljungqvist, and Y. Zhao, 2013: The relationship between the Atlantic Multidecadal Oscillation and temperature variability in China during the last millennium. J. Quat. Sci., 28, 653-658, doi:10.1002/jqs.2658.

,$- \ldots$, C. Qin, S. Kang, M. He, and Z. Wang, 2014: Tree-ring inferred annual mean temperature variations on the southeastern Tibetan Plateau during the last millennium and their relationships with the Atlantic Multidecadal Oscillation. Climate Dyn., 43, 627-640, doi:10.1007/s00382-013-1802-0.

Wang, X., P. M. Brown, Y. Zhang, and L. Song, 2011: Imprint of the Atlantic Multidecadal Oscillation on tree-ring widths in northeastern Asia since 1568. PLoS ONE, 6, E22740, doi:10.1371/ journal.pone.0022740.
Wang, Y., S. Li, and D. Luo, 2009: Seasonal response of Asian monsoonal climate to the Atlantic Multidecadal Oscillation. J. Geophys. Res., 114, D02112, doi:10.1029/2008JD010929.

Wu, B., 2005: Weakening of Indian summer monsoon in recent decades. Adv. Atmos. Sci., 22, 21-29, doi:10.1007/BF02930866.

Wu, G., Y. Liu, B. He, Q. Bao, A. Duan, and F.-F. Jin, 2012: Thermal controls on the Asian summer monsoon. Sci. Rep., 2, 404, doi:10.1038/srep00404.

Yang, B., A. Bräuning, K. R. Johnson, and Y. Shi, 2002: General characteristics of temperature variation in China during the last two millennia. Geophys. Res. Lett., 29, 38-1-38-4, doi:10.1029/2001GL014485.

,-- , and Y. Shi, 2003: Late Holocene temperature fluctuations on the Tibetan Plateau. Quat. Sci. Rev., 22, 2335-2344, doi:10.1016/S0277-3791(03)00132-X.

,,-- Z. Dong, Z. Zhang, and K. Jiao, 2008a: Late Holocene monsoonal temperate glacier fluctuations on the Tibetan Plateau. Global Planet. Change, 60, 126-140, doi:10.1016/ j.gloplacha.2006.07.035.

_ , L. Tang, A. Bräuning, M. E. Davis, J. Shao, and L. Jingjing, 2008b: Summer temperature reconstruction on the central Tibetan Plateau during 1860-2002 derived from annually resolved ice core pollen. J. Geophys. Res., 113, D24102, doi:10.1029/2008JD010142.

— - A. Bräuning, J. Liu, M. E. Davis, and S. Yajun, 2009: Temperature changes on the Tibetan Plateau during the past 600 years inferred from ice cores and tree rings. Global Planet. Change, 69, 71-78, doi:10.1016/j.gloplacha.2009.07.008.

— X. Xang, A. Bräuning, J. Liu, C. Qin, and J. Liu, 2010a: A 622-year regional temperature history of southeast Tibet derived from tree rings. Holocene, 20, 181-190, doi:10.1177/ 0959683609350388.

,-- J. Liu, A. Bräuning, and C. Qin, 2010b: Annual temperature history in southwest Tibet during the last 400 years recorded by tree rings. Int. J. Climatol., 30, 962-971, doi:10.1002/joc. 1956.

, C. Qin, J. Wang, M. He, T. M. Melvin, T. J. Osborn, and K. R. Briffa, 2014: A 3,500-year tree-ring record of annual precipitation on the northeastern Tibetan Plateau. Proc. Natl. Acad. Sci. USA, 111, 2903-2908, doi:10.1073/pnas.1319238111.

Yao, T. D., Z. X. Li, L. G. Thompson, E. M. Thompson, Y. Q. Wang, L. Tian, N. L. Wang, and K. Q. Duan, 2006: $\delta^{18} \mathrm{O}$ records from Tibetan ice cores reveal differences in climatic changes. Ann. Glaciol., 43,1-7, doi:10.3189/172756406781812131.

— , and Coauthors, 2013: A review of climatic controls on $\delta^{18} \mathrm{O}$ in precipitation over the Tibetan Plateau: Observations and simulations. Rev. Geophys., 51, 525-548, doi:10.1002/rog.20023.

You, Q., S. Kang, N. Pepin, and Y. Yan, 2008: Relationship between trends in temperature extremes and elevation in the eastern and central Tibetan Plateau, 1961-2005. Geophys. Res. Lett., 35, L04704, doi:10.1029/2007GL032669.

Zhang, Q. B., G. Cheng, T. Yao, X. Kang, and J. Huang, 2003: A 2,326-year tree-ring record of climate variability on the northeastern Qinghai-Tibetan Plateau. Geophys. Res. Lett., 30, 1739-1742, doi:10.1029/2003GL017425.

Zhu, H., Y. Zheng, X. Shao, X. Liu, Y. Xu, and E. Liang, 2008: Millennial temperature reconstruction based on tree-ring widths of Qilian juniper from Wulan, Qinghai Province, China. Chin. Sci. Bull., 53, 3914-3920, doi:10.1007/s11434-008-0400-8.

_ - X. Shao, Z. Yin, P. Xu, Y. Xu, and H. Tian, 2011: August temperature variability in the southeastern Tibetan Plateau since AD 1385 inferred from tree rings. Palaeogeogr. Palaeoclimatol. Palaeoecol., 305, 84-92, doi:10.1016/j.palaeo.2011.02.017. 